\title{
Auditory maturation and psychological risk in the first year of life
}

Artigo Original

Inaê Costa Rechia ${ }^{1}$

Isabela de Moraes Fattore ${ }^{1}$

Anaelena Bragança de Moraes ${ }^{1}$

Eliara Pinto Vieira Biaggio ${ }^{1}$

Ana Paula Ramos de Souza ${ }^{1}$

\section{Keywords}

Auditory Perception

Child

Risk Indicators

Evoked Potentials

Maturation

\section{Descritores}

Percepção Auditiva

Criança

Indicador de Risco

Potencial Evocado

Maturação

Correspondence address:

Inaê Costa Rechia

Rua Silva Jardim, 1067, Centro, Santa Maria (RS), Brasil, CEP: 97010-491.

E-mail: inaerechia@gmail.com

Received: August 01, 2017

Accepted: November 21, 2017

\section{Maturação auditiva e risco psíquico no \\ primeiro ano de vida}

\begin{abstract}
Purpose: To assess the potential association between psychological risk and limited auditory pathway maturation. Methods: In this longitudinal cohort study, 54 infants (31 non-risk and 23 at-risk) were assessed from age 1 to 12 months. All had normal hearing and underwent assessment of auditory maturation through cortical auditory evoked potentials testing. Psychological risk was assessed with the Child Development Risk Indicators (CDRIs) and PREAUT signs. A variety of statistical methods were used for analysis of results. Results: Analysis of P1 and N1 latencies showed that responses were similar in the both groups. Statistically significant differences between-groups were observed only for the variables N1 latency and amplitude at 1 month. Significant maturation occurred in both groups $(p<0.05)$. There was moderate correlation between P1 latency and Phase II CDRIs, which demonstrates that children with longer latencies at age 12 months were more likely to exhibit absence of these indicators in Phase II and, therefore, were at greater psychological risk. The Phase II CDRIs also correlated moderately with P1 and N1 latencies at 6 months and N1 latencies at 1 month; again, children with longer latency were at increased risk. Conclusion: Less auditory pathway maturation correlated with presence of psychological risk. Problems in the mother-infant relationship during the first 6 months of life are detrimental not only to cognitive development, but also to hearing. A fragile relationship may reflect decreased auditory and linguistic stimulation.
\end{abstract}

\section{RESUMO}

Objetivo: Avaliar a associação entre risco psíquico e maturação da via auditiva. Método: Neste estudo de coorte longitudinal, 54 crianças ouvintes ( $31 \mathrm{sem}$ risco e $23 \mathrm{em}$ risco psíquico) de 1 a 12 meses foram avaliadas. Todas foram submetidas à avaliação da maturação auditiva através dos Potenciais Evocados Auditivos Corticais. O risco psíquico foi avaliado com os Indicadores de Risco de Desenvolvimento Infantil (IRDI) e Sinais PREAUT. Uma variedade de métodos estatísticos foi utilizada para análise de resultados. Resultados: A análise das latências de P1 e N1 mostraram respostas similares entre os grupos. Diferenças estatisticamente significantes entre os grupos foram observadas somente para as variáveis latência e amplitude de N1 no primeiro mês. A maturação auditiva foi significante nos dois grupos $(p<0,05)$. Houve correlação moderada entre latência de P1 e a fase II dos IRDI, demonstrando que crianças com maior latência aos 12 meses apresentaram maior probabilidade de exibir a ausência desses indicadores na Fase II, estando em maior risco psíquico. A fase II dos IRDI também teve correlação moderada com as latências de P1 e N1 aos 6 meses e latências de N1 ao 1 mês; novamente, crianças com latência mais longa estavam em maior risco. Conclusão: A menor maturação auditiva correlacionou-se com a presença de risco psíquico. Problemas na relação mãe-filho durante os primeiros 6 meses de vida são prejudiciais não apenas ao desenvolvimento cognitivo, mas também à audição. Um relacionamento frágil pode refletir diminuição da estimulação auditiva e linguística.

Study conducted at Universidade Federal de Santa Maria - UFSM - Santa Maria (RS), Brasil.

${ }^{1}$ Departamento de Fonoaudiologia, Universidade Federal de Santa Maria - UFSM - Santa Maria (RS), Brasil.

Financial support: nothing to declare.

Conflict of interests: nothing to declare. 


\section{INTRODUCTION}

The auditory system is composed of sensory structures and central connections, which enable peripheral processing and interpretation of auditory (particularly verbal) information; this, in turn, provides access to meaning via language ${ }^{(1)}$.

Thus, an important aspect of any investigation into the language acquisition process is assessment of auditory system maturation. This system, which begins to develop around the 20 th gestational week, continues to specialize during extrauterine life, until 2 years of age, with the acquisition of skills such as sound detection, discrimination, and localization ${ }^{(1)}$. Hence, it is pertinent that both processes - language acquisition and auditory maturation - be monitored in infants, particularly during the first 2 years of life, a period during which the neuroplasticity of the auditory system allows structural and functional changes to take place depending on the type of auditory stimulation provided to the child ${ }^{(2)}$.

Auditory pathway maturation can be assessed by cortical evoked potentials testing, a procedure that can be performed at various stages of child development, both in normal-hearing infants and in cochlear implant recipients or hearing aid users ${ }^{(3,4)}$. While still in the mother's womb, an infant is able to hear her voice and discriminate sounds. Studies have shown that both the mother's voice and the voices of others are heard in utero, and that even prosodic features of speech are perceived ${ }^{(5)}$. Other research showed that newborns preferred to hear a story their mother had read aloud six weeks prior to birth, than one they had never heard. Prenatal learning of some acoustic features of the story, probably prosodic, may explain this preference ${ }^{(5)}$.

Therefore, both hearing and language acquisition depend on the availability of opportunities for the infant to experience communication through verbal and nonverbal interactions with the mother, interactions that begin even before birth. Access to meaning in language, however, will depend on processes such as homology and interpretance, whereby the mother attributes meaning to the infant's (initially nonverbal) manifestations ${ }^{(6)}$. The work of these authors demonstrates that, the more a mother speaks in tune with her child's manifestations, the more the child will function in language, thereby accessing the linguistic interpretation he is given, which is reflected by increased babbling. Babbling is an important milestone toward speech production ${ }^{(7)}$.

In this initial "proto-conversation", the mother not only conveys linguistic messages, providing access to the semiotic level of language ${ }^{(6)}$, but also shows her desire for the child through a very particular form of expression: motherese ${ }^{(8)}$. Motherese emerges when the adult-infant relationship is "good enough" ${ }^{(8)}$ to allow establishment of alienation/separation processes as expected, through exercise of the maternal and paternal functions and operationalization of key axes: demand establishment, individual assumption (the anticipation of the presence of a individual in the child), alternating presence and absence (of the mother or important other), and the possibility of otherness (which entails the infant's knowing that he is a separate entity from his mother or important other).

If these subjective processes do not occur in a "good enough" manner, the infant's psychological development may be at risk, which may be reflected by an absence of motherese, by an absence of speech patterns attuned to the infant's demands by the mother or important other, or even by silence, when the parent or adult is unable to interpret the infant's demands ${ }^{(9)}$. This would hinder sustained enunciation by the infant and lead to reduced auditory stimulation. In addition to the problems that arise due to parental difficulties, there is another type of psychological risk whose origin lies in difficulties with the baby such as autism. In the specific case of autism, the dialogue between mother and at-risk infant takes the shape of an unanswered, un-echoed utterance due to congenital difficulties with the baby, an utterance that never becomes a message to be decoded ${ }^{(10)}$. This reduces maternal investment and hinders emergence of inter-subjective behavior in the second semester of life $\mathrm{e}^{(11)}$.

Considering the afore mentioned theoretical axes relevant to linguistic development, two protocols for assessment of psychological risk have been created (one in Brazil, one in France) and validated for use in our reality: the Child Development Risk Indicators (CDRIs) ${ }^{(12)}$ and the PREAUT signs $^{(13)}$. The CDRIs comprise 18 indicators designed to detect risk of distinct psychopathological conditions in four age ranges. The PREAUT signs are a smaller set of indicators, administered at ages 4 and 9 months, designed with the specific objective of detecting a risk of autism ${ }^{(14)}$.

Several studies have demonstrated that these protocols are capable of detecting whether the relationship between mother (or important other) and infant is progressing well and whether the paternal function is operating. CDRI-based studies have reported associations of developmental risk with maternal emotional states, difficulty exercising the maternal function, feeding difficulties in the infant ${ }^{(15)}$, language acquisition ${ }^{(16)}$, and several sociodemographic and psychosocial variables ${ }^{(17)}$.

Many individuals diagnosed with autism experience auditory hypersensitivity. This condition hinders meaningful processing of language ${ }^{(18)}$ and can cause irritability, pain, and, in some cases, extreme fear ${ }^{(19)}$. Although ongoing research is seeking to develop tests to measure hearing sensitivity in people with autism, there is ample room for further investigation. Sensory processing deficits are common in autism spectrum disorders, but the underlying mechanisms are unclear. One study demonstrated increased cortical neuron excitability in response to sound stimuli, which suggests that cortical responses to repeated sounds may feature abnormal habituation. These authors used cortical evoked potentials testing to assess which changes occur at the N1 amplitude with auditory habituation in children on the autism spectrum ${ }^{(20)}$. Such abnormalities were also observed in this population on brainstem auditory evoked potentials (BAEP), middle-latency auditory evoked potentials, and the P300 response ${ }^{(21)}$.

The neuronal connectivity abnormalities of autism are characterized by excess local connections and breakdown of long-distance connections between different regions of the brain. The connectivity disorder hypothesis for autism is consistent with the fact that, although the sensory organs and senses themselves (e.g., seeing and hearing) are not defective in autism, these children do not place any particular emphasis on the human voice or face, considering the complexity of meanings 
which they convey. Despite normal audiometry findings, autistic children appear deaf to their parents, given that they do not react to the human voice as typically developing infants $\mathrm{do}^{(22)}$.

Taking this theoretical framework into consideration, we hypothesized that children at psychological risk, be it autistic or not, in the first year of life might exhibit less auditory maturation when compared with not at risk children. Thus, the objective of the present study was to analyze the potential association between presence of psychological risk and lessened auditory pathway maturation.

\section{METHODS}

This study was part of a larger project, "Análise Comparativa do Desenvolvimento de Bebês Prematuros e a Termo e sua Relação com Risco Psíquico: da detecção à intervenção", which was authorized in May 2014 by the relevant institutional Research Ethics Committee with judgment number 28586914.0.0000.5346. All those responsible for the individuals involved signed the Informed Consent Term. All standards and guidelines for human individuals research established in the Brazilian National Health Council Resolution No. 466/12 were followed, including provisions for data confidentiality and individual privacy.

The sample comprised normal-hearing neonates seen at the Newborn Hearing Screening program at a university hospital. Originally, 305 neonates were invited to participate, but 180 were not brought for baseline assessment.

The inclusion criteria were: having passed both bilateral transient evoked otoacoustic emissions (TEOAEs) and automated auditory brainstem response (ABR) testing on newborn hearing screening; and having a type A tympanogram at the time of assessment. The choice of the procedure to be used (TEOAE or ABR) was based on the analysis of risk indicators for hearing impairment ${ }^{(23)}$.

Infants who failed to attend any of the assessment visits were excluded from analysis, as were those with organic syndromes, those whose mothers had severe mental disorders, and those who failed hearing screening. These criteria were assessed by the multidisciplinary research team, which included Psychologists, Speech-language pathologists, Physical therapists, and Occupational therapists. All infants also underwent medical assessment by a pediatrician, as well as neurological examination and genetic evaluation as needed.

Considering the aforementioned eligibility criteria, the initial sample comprised 125 neonates who underwent cortical auditory evoked potentials (CAEPs) testing during the first month of life. However, 30 newborns were excluded due to excess artifacts $(>10 \%)$ on CAEP recordings. Furthermore, a significant portion of the sample was lost during follow-up due to changes of address/phone number or parental dropout. The final sample comprised 54 infants: 31 in the no-risk control group and 23 in the at-risk study group. The psychological risk was defined by CDRIs ${ }^{(12)}$ and the PREAUT signs ${ }^{(24)}$.

The CDRIs are 18 indicators which can be visualized during mother-child interactions over four age ranges (0-4, 4-8, 8-12, and 12-18 months), and are designed to assess whether the infant is at risk of severe psychopathology or whether any problems in the mother-child relationship may have constituted a hindrance to infant development, i.e., aspects related to psychic constitution. These indicators were scored during the interview with parents and observed on 15-minute videos obtained at 3, 6, 9, and 12 months. During the 3-and 6-month assessments, the infant was placed in a car seat for face-to-face interaction with the mother, who was asked to sing, talk, and play with a rubber toy with her child. At the 9- and 12-month assessments, depending on the infant's psychomotor development, the infant was sat on a foam mat with its mother and allowed to move around with access to a box of rubber toys, including animals, foods, household utensils, dolls, vehicles, and a bottle. At these ages, interactions were not entirely free. Footage was obtained with two cameras: one placed at a distance of $1 \mathrm{~m}$ to provide a lateral view of the infant's face-to-face interaction with his mother and one placed at a distance of $2 \mathrm{~m}$ to provide a frontal view of the infant's face during interactions. The mother's face was visible on a mirror placed behind the car seat. At the 9-and 12-month assessments, infants were also visible on the mirror while moving around on the mat.

Infants in whom at least two indicators were absent at any phase were considered to be at risk. Analysis of correlation between the CDRIs and auditory pathway maturation took into account the phase I, II, and IV indicators and the auditory assessments performed on the same day (1-month, 6-month, and 12-month visits).

The PREAUT signs, that seek to detect autism risk, were administered in two phases, at 4 and 9 months, and consisted of observing the infant's reactions to motherese (spoken by the mother and by the investigator) and the infant's attempts to seek the adult's attention after cessation of motherese. One point was scored for each item present. If the score was $<5$ points, the second part of the questionnaire was administered. Scores below 5 points are indicative of risk of progression to full-blown autism. Preliminary validation studies of the PREAUT signs suggest that, although reasonably sensitive and specific for detection of risk of autism ${ }^{(14)}$, the signs can also detect other developmental disorders, including language disorders and risk of psychosis $^{(13)}$. We also checked for the PREAUT signs during the interview and on the interaction footage. Signs were considered in relation to the auditory maturation process, as audiological examinations were not performed on the same day.

CAEPs were performed to assess auditory maturation at 1,6 , and 12 months. Audiological assessment was performed before age 1 month to ensure that all infants in the sample exhibited the components of interest (P1N1).

Auditory pathway maturation was assessed by CAEP testing. This was performed with a two-channel SmartEP system (Intelligent Hearing Systems/Interacoustics). The skin was prepared with NuPrep abrasive gel and the CAEP electrodes placed at positions $\mathrm{Fz}$ (positive), Fpz (ground), M1 (left mastoid), and M2 (right mastoid). The stimulus parameters used for CAEP acquisition were based on a previous study performed at the same facility, using the same system ${ }^{(25)}$ oddball paradigm, CV syllable pairs (standard $\backslash \mathrm{ba} \backslash$ and deviant $\backslash \mathrm{ga} \mid$ ), binaural presentation, at a fixed intensity of $70 \mathrm{~dB} n \mathrm{~nL}$ rarefaction polarity, with a $1-30 \mathrm{~Hz}$ filter, 
using insert earphones. The maximum acceptable artifact rate was 10\%. Approximately 150 stimuli (30 deviants) were presented.

The term P1 was used for the highest positive peak and N1 the highest deflection after P1. For the labeling of the P1-N1 complex, the tracing of the frequent stimulus was used ${ }^{(26)}$. The absolute latency of the P1, N1 components in milliseconds $(\mathrm{ms})$ and a P1-N1 amplitude in microvolt $(\mu \mathrm{V})$ was determined considering a peak amplitude over time. The exams were analyzed by two trained judges with theoretical/practical knowledge in electrophysiology of hearing, especially PEALL. The judges performed the marks of the components of this potential in a blind way, that is, they performed as independent marks, without printed records of the exams. Subsequently, given that the researchers reproduced these marks in the respective examinations, there is no software for the equipment in question to precisely obtain latency and amplitude values.

To analyze auditory maturation, we calculated the difference between P1N1 latencies during the first, second, and third time points of assessment, as reported by other authors ${ }^{(27)}$.

At the 6- and 12-month assessments, infants were offered a tablet computer on which they could watch videos to help them remain calm during the tests.

To rule out middle ear disorders, tympanometry was performed (OTOflex 100 handheld immitance test device, GN Otometrics) before all CAEP tests. Infants who exhibited tympanometric abnormalities were immediately referred for ENT evaluation and later returned for a new round of audiological assessment.

The sample was assessed from age 0 to 12 months. Protocols for assessment of developmental risk were administered at least once every 3 months, while CAEP testing for auditory pathway maturation was performed every 6 months.

For statistical analysis, results were entered into a Microsoft Excel spreadsheet and nonparametric tests were performed in STATA 9.0 to compare the variables of interest between the study (at-risk) and control (no-risk) groups.

Nominal and ordinal analyses were performed where appropriate to allow calculation of the Mann-Whitney $U$ test, Spearman correlation coefficients, and the Wilcoxon test. The significance level for all tests was set at 5\% (0.05), and all confidence intervals were created at the $95 \%$ level.

\section{RESULTS}

Analysis of P1 and N1 latencies showed that responses were similar in the control and study groups. Statistically significant between-group differences were observed only for the variables N1 latency (left ear) and amplitude (right ear) at 1 month (Table 1).

Table 1. Analysis of P1 and N1 latencies between groups

\begin{tabular}{|c|c|c|c|}
\hline \multirow{2}{*}{ Variable } & Study group $(n=23)$ & Control group $(n=31)$ & \multirow{2}{*}{$p$-value } \\
\hline & Mean \pm SD & Mean \pm SD & \\
\hline \multicolumn{4}{|c|}{ P1 latency (ms), month 1} \\
\hline RE & $228.4 \pm 33.0$ & $213.1 \pm 53.2$ & 0.404 \\
\hline LE & $229.8 \pm 37.4$ & $207.4 \pm 53.2$ & 0.165 \\
\hline \multicolumn{4}{|c|}{$\mathrm{N} 1$ latency (ms), month 1} \\
\hline RE & $394.4 \pm 73.6$ & $357.7 \pm 70.5$ & 0.100 \\
\hline LE & $407.2 \pm 74.0$ & $358.6 \pm 75.0$ & $0.044^{*}$ \\
\hline \multicolumn{4}{|c|}{ P1-N1 amplitude (mV), month 1} \\
\hline RE & $8.7 \pm 6.0$ & $6.0 \pm 3.5$ & $0.022^{*}$ \\
\hline LE & $8.2 \pm 4.0$ & $6.5 \pm 4.6$ & 0.057 \\
\hline \multicolumn{4}{|c|}{ P1 latency (ms), month 6} \\
\hline RE & $147.2 \pm 51.0$ & $137.7 \pm 34.6$ & 0.384 \\
\hline LE & $146.8 \pm 51.1$ & $142.0 \pm 33.7$ & 0.801 \\
\hline \multicolumn{4}{|c|}{ N1 latency (ms), month 6} \\
\hline RE & $247.8 \pm 67.4$ & $235.5 \pm 44.9$ & 0.660 \\
\hline LE & $253.1 \pm 69.9$ & $232.1 \pm 41.8$ & 0.209 \\
\hline \multicolumn{4}{|c|}{ P1-N1 amplitude (mV), month 6} \\
\hline RE & $11.8 \pm 10.2$ & $9.8 \pm 8.5$ & 0.840 \\
\hline LE & $14.1 \pm 13.7$ & $12.8 \pm 10.7$ & 0.618 \\
\hline \multicolumn{4}{|c|}{ P1 latency (ms), month 12} \\
\hline RE & $110.8 \pm 25.1$ & $106.1 \pm 22.2$ & 0.706 \\
\hline LE & $108.2 \pm 25.3$ & $108.1 \pm 19.1$ & 0.914 \\
\hline \multicolumn{4}{|c|}{$\mathrm{N} 1$ latency (ms), month 12} \\
\hline RE & $184.5 \pm 39.8$ & $180.2 \pm 39.0$ & 0.753 \\
\hline LE & $181.3 \pm 37.8$ & $179.7 \pm 38.3$ & 0.900 \\
\hline \multicolumn{4}{|c|}{ P1-N1 amplitude (mV), month 12} \\
\hline $\mathrm{RE}$ & $8.1 \pm 6.8$ & $7.9 \pm 7.1$ & 0.706 \\
\hline LE & $9.5 \pm 7.2$ & $7.5 \pm 5.5$ & 0.177 \\
\hline
\end{tabular}

Mann-Whitney $U$ test; * $p \leq 0.050$

Caption: RE - right ear; LE - left ear; ms - milliseconds; $\mathrm{mV}$ - microvolts; SD - standard deviation 
In this study, analysis of the waveforms of interest (P1N1) was performed in double-blind fashion to ensure the reliability of results. Nevertheless, there was wide variability in response across the infants in the sample, as demonstrated by the standard deviation values.

"Auditory maturation" was defined as the difference between the latencies of P1 from the first to the sixth month, from the sixth to the twelfth month, and from the first to the twelfth month. Table 2 lists the mean latencies measured at each time point in the study and control groups, which show that statistically significant maturation occurred in both groups $(p<0.05)$. Separate values for the right and left ears are not provided, as there was no significant difference (Table 2).

Table 3 lists those variables for which correlations were found. There was moderate correlation between P1 latency and Phase II CDRIs, which demonstrates that children with longer latencies at age 12 months were more likely to exhibit absence of these indicators in Phase II and, therefore, were at greater psychological risk. The Phase II CDRIs also correlated moderately with $\mathrm{P} 1$ and $\mathrm{N} 1$ latencies at 6 months and N1 latencies at 1 month; again, children with longer latency were at increased risk.

The Phase IV CDRIs exhibited a similar but inverse correlation with N1 latencies, i.e., children at greater developmental risk had lower latencies. It is worth noting that two parallel processes were observed in this sample: a reduction in the number of at-risk infants at 12 months and an absence of between-group difference in latencies at this age.

Table 4 shows the frequency of psychological risk at each time point of assessment, as evaluated by the CDRIs and PREAUT signs. A substantial reduction in the total number of at-risk infants was observed with both protocols at the last time point. This progression is depicted in Figure 1.

Table 2. Analysis of auditory maturation between time points of CAEP testing in the study and control groups

\begin{tabular}{|c|c|c|c|c|}
\hline & Study group $(n=23)$ & \multirow{2}{*}{$p$-value } & Control group $(n=31)$ & \multirow{2}{*}{$p$-value } \\
\hline & Mean \pm SD & & Mean \pm SD & \\
\hline \multicolumn{5}{|l|}{1 to 6 months } \\
\hline P1 latency (ms) & $86.0 \pm 73.1$ & $<0.001^{\star}$ & $99.9 \pm 44.2$ & $<0.001^{*}$ \\
\hline N1 latency (ms) & $153.7 \pm 95.7$ & $<0.001^{*}$ & $163.0 \pm 91.1$ & $<0.001^{*}$ \\
\hline \multicolumn{5}{|l|}{6 to 12 months } \\
\hline P1 latency (ms) & $41.9 \pm 49.4$ & $<0.001^{\star}$ & $30.2 \pm 23.8$ & $<0.001^{*}$ \\
\hline P1 latency (ms) & $107.9 \pm 56.1$ & $<0.001^{\star}$ & $112.6 \pm 37.7$ & $<0.001^{*}$ \\
\hline $\mathrm{N} 1$ latency (ms) & $186.3 \pm 68.5$ & $<0.001^{*}$ & $177.5 \pm 82.2$ & $<0.001^{*}$ \\
\hline
\end{tabular}

Wilcoxon test; * $\mathrm{p}<0.050$

Caption: ms- miliseconds; SD- standard deviation

Table 3. Correlation between variables of interest in the study and control groups

\begin{tabular}{|c|c|c|c|c|}
\hline & \multicolumn{2}{|c|}{ Study group $(n=23)$} & \multicolumn{2}{|c|}{ Control group $(n=31)$} \\
\hline & $\mathrm{R}$ & $p$-value & $\mathrm{R}$ & $\mathrm{p}$-value \\
\hline \multicolumn{5}{|l|}{1 month } \\
\hline P1 × CDRls, Phase I & -0.009326 & 0.973684 & 0.149646 & 0.429950 \\
\hline P1 × CDRls, Phase II & 0.084221 & 0.765385 & - & - \\
\hline P1 × CDRls, Phase III & 0.174611 & 0.533673 & 0.079339 & 0.676862 \\
\hline P1 × CDRls, Phase IV & 0.071340 & 0.800538 & -0.225369 & 0.231141 \\
\hline P1 $\times$ PREAUT, 4 months & 0.240186 & 0.388544 & -0.192998 & 0.306864 \\
\hline P1 $\times$ PREAUT, 9 months & 0.159397 & 0.570420 & -0.010732 & 0.955115 \\
\hline N1 × CDRls, Phase I & 0.002793 & 0.992118 & -0.037688 & 0.843261 \\
\hline N1 × CDRls, Phase II & -0.466294 & 0.049770 & - & - \\
\hline N1 × CDRls, Phase III & -0.298091 & 0.280536 & 0.067982 & 0.721134 \\
\hline N1 × CDRls, Phase IV & 0.101076 & 0.720027 & -0.053641 & 0.778308 \\
\hline N1 $\times$ PREAUT, 4 months & 0.078655 & 0.780526 & -0.107229 & 0.572758 \\
\hline N1 $\times$ PREAUT, 9 months & 0.098689 & 0.726399 & -0.311120 & 0.094231 \\
\hline \multicolumn{5}{|l|}{6 months } \\
\hline P1 × CDRls, Phase I & 0.183385 & 0.402269 & 0.186909 & 0.314027 \\
\hline P1 × CDRls, Phase II & -0.467000 & $0.024664^{*}$ & - & - \\
\hline P1 × CDRls, Phase III & 0.006837 & 0.975300 & 0.093212 & 0.617962 \\
\hline P1 × CDRls, Phase IV & -0.062294 & 0.777665 & 0.132761 & 0.476485 \\
\hline
\end{tabular}

Spearman correlation coefficient; ${ }^{*} p<0.050$

Caption: CDRI - Child Development Risk Indicators; $R$ - correlation coefficient 
Table 3. Continued...

\begin{tabular}{|c|c|c|c|c|}
\hline & \multicolumn{2}{|c|}{ Study group $(n=23)$} & \multicolumn{2}{|c|}{ Control group $(n=31)$} \\
\hline & $\mathrm{R}$ & $p$-value & $\mathrm{R}$ & $\mathrm{p}$-value \\
\hline P1 $\times$ PREAUT, 4 months & 0.305451 & 0.156385 & -0.027274 & 0.884204 \\
\hline P1 $\times$ PREAUT, 9 months & 0.030587 & 0.889811 & 0.040850 & 0.827285 \\
\hline N1 $\times$ CDRls, Phase I & 0.290896 & 0.178101 & 0.251532 & 0.172258 \\
\hline N1 × CDRls, Phase II & -0.490541 & $0.017477^{*}$ & - & - \\
\hline N1 × CDRls, Phase III & -0.045400 & 0.837032 & 0.073596 & 0.693981 \\
\hline $\begin{array}{c}\mathrm{N} 1 \times \text { PREAUT, } 9 \text { months } \\
12 \text { months }\end{array}$ & 0.106056 & 0.630074 & 0.204268 & 0.270351 \\
\hline P1 × CDRls, Phase I & 0.189956 & 0.385318 & 0.352093 & 0.052073 \\
\hline P1 × CDRls, Phase II & -0.475565 & $0.021817^{*}$ & - & - \\
\hline P1 × CDRls, Phase III & 0.170785 & 0.435903 & -0.068731 & 0.713331 \\
\hline N1 × CDRls, Phase I & -0.344995 & 0.106915 & 0.189764 & 0.306558 \\
\hline N1 $\times$ CDRls, Phase II & -0.215600 & 0.323151 & - & - \\
\hline N1 × CDRls, Phase III & 0.177681 & 0.417312 & -0.171654 & 0.355835 \\
\hline N1 × CDRls, Phase IV & 0.608049 & $0.002084^{*}$ & -0.285860 & 0.119013 \\
\hline N1 $\times$ PREAUT, 4 months & -0.167838 & 0.443981 & -0.155270 & 0.404249 \\
\hline N1 $\times$ PREAUT, 9 months & 0.060573 & 0.783661 & 0.030628 & 0.870078 \\
\hline
\end{tabular}

Spearman correlation coefficient; ${ }^{*} p<0.050$

Caption: CDRI - Child Development Risk Indicators; $R$ - correlation coefficient

Table 4. Frequency of risk stratified by indicator

\begin{tabular}{|c|c|c|c|c|}
\hline \multirow{2}{*}{ CDRI } & \multicolumn{2}{|c|}{ Not at risk } & \multicolumn{2}{|c|}{ At risk } \\
\hline & $n$ & $\%$ & $n$ & $\%$ \\
\hline Phase I & 31 & 57.41 & 23 & 42.59 \\
\hline Phase II & 43 & 79.63 & 11 & 20.37 \\
\hline Phase III & 38 & 70.38 & 16 & 29.62 \\
\hline Phase IV & 46 & 85.18 & 8 & 14.81 \\
\hline PREAUT, 4 months & 31 & 57.41 & 23 & 42.59 \\
\hline PREAUT, 9 months & 43 & 79.63 & 11 & 20.37 \\
\hline
\end{tabular}

Descriptive analysis of data

Caption: CDRI - Child Development Risk Indicators

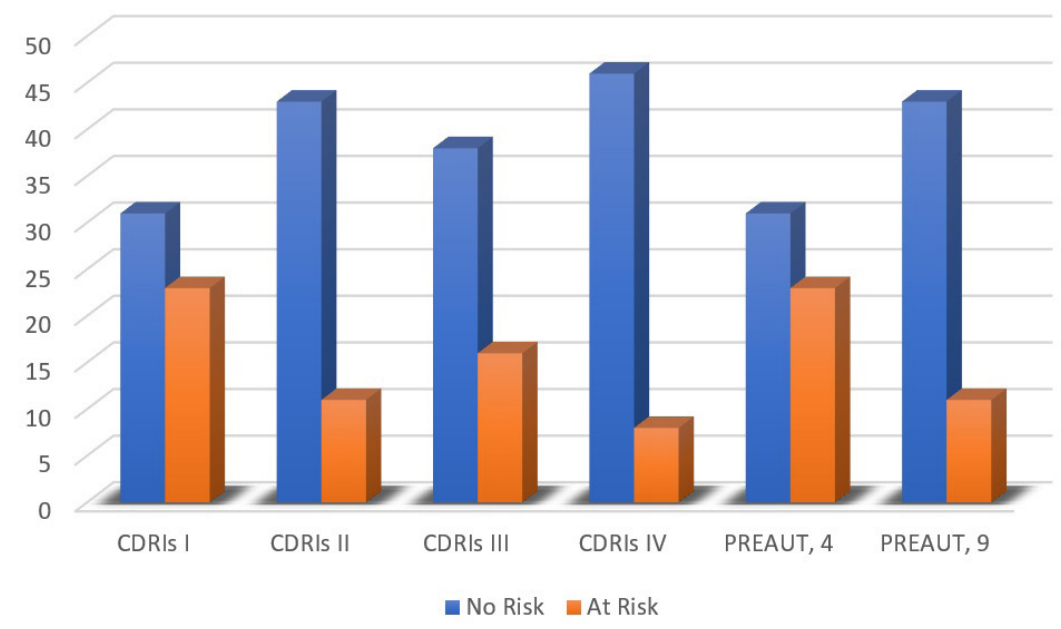

Figure 1. Progression of developmental risk in the sample 


\section{DISCUSSION}

The results of this study demonstrate the relevance of cortical auditory evoked potentials as a biomarker of auditory maturation. In our sample, maturation was observed at all three assessment time points (1, 6, and 12 months), i.e., 12-month-old infants had lower latencies than at 1 and 6 months of age, and the progression from one time point to the next was statistically significant. These findings corroborate the results of other studies in which CAEPs were used to evaluate children with auditory neuropathy ${ }^{(3)}$ and sensorineural hearing $\operatorname{loss}^{(4)}$. CAEP testing has shown that P1 latency decreases substantially after cochlear implant activation. These authors also report that earlier timing of activation (before age 2 years) is associated with greater likelihood of normal cortical responses, improved speech perception, and greater development of hearing skills and oral language ${ }^{(28)}$.

This study focused on analysis of the P1N1 components; the P2N2 components were not assessed because, prior to 24 months, there is no neural substrate for their development. Authors who use the term "P2N2" are employing a nomenclature based on the latency of CAEP components. Several factors can influence detection of specific CAEP components, including age, which reflects the maturation of the neural processes that generate the evoked potential response. Peak amplitude, for instance, is greatly dependent on synaptic density in the primary auditory cortex. This amplitude doubles over the course of the first 3 months of life. With advancing age, neural synchrony also increases, which may result in greater response. The magnitude of potentials recorded over time may also be influenced by neural substrates ${ }^{(29)}$.

Comparison between the control (no risk) and study (at-risk) groups did not reveal significantly different responses, because both groups exhibited similar latencies at each phase of the study. However, when testing for correlation between auditory maturation and psychological risk, we found that at-risk infants exhibited less maturation than control infants, both from month 1 to month 6 and from month 6 to month 12. This suggests that infants at psychological risk may have slowed auditory maturation compared with controls not at risk.

Analysis of correlation between CDRI phases I and II and CAEP findings at month 1 vs. month 6 also confirmed this, showing that, in the first semester of life, infants at psychological risk may have experienced less maturation due to disordered relationships with their primary caregivers, i.e., their mothers. This confirms our initial research hypothesis that children at psychological risk may be receiving or processing less auditory and linguistic stimulation, as demonstrated in previous studies using the CDRIs ${ }^{(9,16)}$. It is worth noting that the number of at-risk infants was 23 in phase I and 11 in phase II. What appears to be at stake is the possibility of at-risk infants progressing or not from a condition of hearing to one of listening.

On the other hand, studies have hypothesized that infants at risk of autism may have abnormal auditory processing ${ }^{(20,21)}$. At age 4 months, 23 infants exhibited abnormalities in the PREAUT protocol, while at 9 months, 11 infants were considered at-risk due to absence of PREAUT signs. These numbers coincide with the number of infants at risk by the CDRI protocol, which was expected due to the strong agreement between the two protocols (CDRI and PREAUT), as demonstrated by another study ${ }^{(30)}$.

As no outcomes were assessed in the infants, we cannot affirm that a diagnosis for autism or another psychopathology would explain a lower degree of maturation. However, we can state that the negative effects on auditory maturation of insufficient or inadequate stimuli (when the problem is related to an inability of the mother to play her role $\left.{ }^{(12)}\right)$ or of the infant's inability to connect to his mother's voice (when the problem is risk of autism ${ }^{(22)}$ ) can be assessed by CAEP testing. Outcome assessment (i.e., testing for psychopathological diagnoses) at 24 and 36 months and follow-up audiological assessments at these ages, as we plan to do within the context of this project, may contribute to detection of between-group differences.

Finally, it is interesting to note that, at age 12 months, we observed an inverse phenomenon: infants with lower latency were at greater risk. There are two processes at play in this finding. First, despite the absence of a statistical difference between the study and control groups, latencies were lower in 8 infants with abnormal CDRIs and 11 infants with abnormal PREAUT signs. Our data suggests that a greater number of altered PREAUT signs will contribute to increased sensitivity to sound, particularly in the left ear, in which processing involves the right hemisphere of the brain. One may hypothesize that precarious reactions to another human being, and particularly to the human voice, may limit hemispheric specialization for language and lead to heightened auditory reactions in the left ear (right hemisphere). Therefore, lower auditory latency cannot be deemed to equate with better language performance. It may however, be related to increased hearing sensitivity. Although this may appear to represent an auditory advantage and could even explain the facility of autistic children for rhythm and music ${ }^{(18,19)}$, at least in the 11 cases in our sample, it may not correspond to good language processing, as the perception of auditory stimuli was not followed by the formation of the symbolism necessary for linguistic interpretation. This is consistent with the literature on autism $^{(20)}$. We may infer that at-risk infants at age 12 months, although not at a disadvantage when hearing, are experiencing difficulty listening, as their linguistic functioning in dialogue scenarios is precarious.

Thus, in infants not at risk, slightly longer latencies may be indicative of additional linguistic effort for processing of auditory information. This hypothesis should be confirmed by continued follow-up of language acquisition in these infants and further research in larger samples.

\section{CONCLUSION}

The objective of the present study was to test for association between psychological risk and auditory pathway maturation. We were able to establish a correlation between these variables, even if it was not substantial. Our findings demonstrated that a troubled mother-infant relationship during the first semester of life is not only harmful to psychic development, but can also be reflected in auditory development (since the study group had higher latencies than the control group) and less symbolic use of information at age 12 months, at which point auditory 
processing gains speed but language interpretation may be poorer in the at-risk group.

Our results highlight the importance of assessing auditory maturation in infants at psychological risk, because normal hearing does not ensure quality of language acquisition.

\section{REFERENCES}

1. Moore JK, Ponton CW, Eggermont JJ, Wu BJ, Huang JQ. Perinatal maturation of the auditory brain stem response: changes in path length and conduction velocity. Ear Hear. 1996;17(5):411-8. http://dx.doi.org/10.1097/00003446199610000-00007. PMid:8909889.

2. Northern JL, Downs MP. Audição na infância. Rio de Janeiro: Guanabara Koogan; 2005.

3. Cardon G, Sharma A. Central auditory maturation and behavioral outcome in children with auditory neuropathy spectrum disorder who use cochlear implants. Int J Audiol. 2013;52(9):577-86. http://dx.doi.org/10.3109/149 92027.2013.799786. PMid:23819618.

4. Alvarenga KF, Vicente LC, Lopes RC, Ventura LM, Bevilacqua MC, Moret AL. Desenvolvimento do potencial evocado auditivo cortical P1 em crianças com perda auditiva sensorioneural após o implante coclear: estudo longitudinal. CoDAS. 2013;25:521-6. PMid:24626977.

5. Boysson-Bardies B, Schonen S, Jusczyk P, McNeilage P, Morton J. Developmental Neurocognition: speech and face processing in the first year of life. Kluwer Academic Publishes; 1993. http://dx.doi.org/10.1007/97894-015-8234-6.

6. Kruel CS, Rechia IC, Oliveira LD, Souza APR. Enunciative categories in the description of language functioning of mothers and infants aged 1-4 months. CoDAS. 2016;28(3):244-51. http://dx.doi.org/10.1590/23171782/20162015190. PMid:27462732.

7. D'Odorico L, Majorano M, Fasolo M, Salerni N, Suttora C. Characteristics of phonological development as a risk factor for language development in Italian-speaking pre-term children: A longitudinal study. Clin Linguist Phon. 2011;25(1):53-65. http://dx.doi.org/10.3109/02699206.2010.5117 59. PMid:21080829.

8. Kruel CS, Souza APR. Experiência mãe-bebê de mutualidade expressa em sistemas semióticos verbais e não-verbais. Psic. Teor. Pesq. 2017 (no prelo).

9. Flores MR, Beltrami L, Ramos AP. O manhês e suas implicações para a constituição do sujeito na linguagem. Distúrb Comun. 2011;23:143-52.

10. López ALL. A escuta psicanalítica de uma criança autista. Estud Psicanál. 2010;34:3-20.

11. Saint-Georges C, Mahdhaoui A, Chetouani M, Cassel RS, Laznik MC, Apicella F, et al. Do parents recognize autistic deviant behavior long before diagnosis? Taking into account interaction using computational methods. PLoS One. 2011;6(7):e22393. http://dx.doi.org/10.1371/journal. pone.0022393. PMid:21818320.

12. Kupfer MCM, Jerusalinsky AJ, Bernardino LMF, Wanderley D, Rocha PSB, Molina SE, et al. Predictive value of clinical risk indicators in child development: final results of a study based on psychoanalytic theory. Rev Latinoam Psicopatol Fundam. 2010;13(1):31-52. http://dx.doi.org/10.1590/ S1415-47142010000100003.

13. Crespin G, Parlato-Oliveira EPO. Projeto PREAUT. In: Jerusalinsky A, editor. Austism dossier. São Paulo: Instituto Langage; 2015. p. 437-455.

14. Ouss L, Saint-Georges C, Robel L, Bodeau N, Laznik MC, Crespin GC, et al. Infant's engagement and emotion as predictors of autism or intellectual disability in West syndrome. Eur Child Adolesc Psychiatry. 2014;23(3):1439. http://dx.doi.org/10.1007/s00787-013-0430-x. PMid:23728914.

15. Vendrúscolo JF, Bolzan GM, Crestani AH, Souza APR, Moraes AB. A relação entre o aleitamento, transição alimentar e osindicadores de risco para o desenvolvimento infantil. Distúrb Comun. 2012;24:41-2.
16. Crestani AH, Moraes AB, Souza APR. Análise da associação entre índices de risco ao desenvolvimento infantil e produção inicial de fala entre 13 e 16 meses. Rev CEFAC. 2015;17(1):169-76. http://dx.doi.org/10.1590/1982021620153514 .

17. Crestani AH, Oliveira LD, Vendruscolo JF, Ramos-Souza AP. Distúrbio específico de linguagem: a relevância do diagnóstico inicial. Rev CEFAC. 2013;15(1):228-37. http://dx.doi.org/10.1590/S1516-18462012005000105.

18. Gomes E, Pedroso FS, Wagner MB. Auditory hypersensitivity in the autistic spectrum disorder. Pro Fono. 2008;20(4):279-84. http://dx.doi.org/10.1590/ S0104-56872008000400013. PMid:19142473.

19. Morris R. Managing sound sensitivity in autism spectrum disorder: new technologies for customized intervention [thesis]. Cambridge (MA): Massachusetts Institute of Technology; 2009. 86 p.

20. Lovelace JW, Wen TH, Reinhard S, Hsu MS, Sidhu H, Ethell IM, et al. Matrix metalloproteinase-9 deletion rescues auditory evoked potential habituation deficit in a mouse model of Fragile X Syndrome. Neurobiol Dis. 2016;89:126-35. http://dx.doi.org/10.1016/j.nbd.2016.02.002. PMid:26850918.

21. Magliaro FC, Scheuer CI, Assumpção FB Jr, Matas CG. Estudo dos potenciais evocados auditivos em autismo. Pro Fono. 2010;22(1):31-6. http://dx.doi.org/10.1590/S0104-56872010000100007. PMid:20339805.

22. Muratori F. O diagnóstico precoce no autismo: guia prático para pediatras. Salvador: Núcleo Interdisciplinar de Intervenção Precoce de Bahia; 2014

23. American Academy of Pediatrics, Joint Committee on Infant Hearing. Year 2007 position statement: principles and guidelines for early hearing detection and intervention programs. Pediatrics. 2007;120(4):898-921. http://dx.doi.org/10.1542/peds.2007-2333. PMid:17908777.

24. Associaciòn Prèaut. 2012 [cited 2012 Feb 22]. Available from: http://www. preaut.fr/

25. Melo A, Sleifer P, Rechia IC, Biaggio EPV. Cortical auditory evoked potentials in full term and preterm neonates: gender and risk factors for hearing impairment. Audiol Commun Res. 2016;21:e1645.

26. McPherson DL. Late potentials of the auditory system. San Diego, CA: Singular Publishing Group. 1996.

27. Costa LD, Quinto SMS, Didoné DD, Rechia IC, Garcia MV, Biaggio EPV. Audição e linguagem em crianças nascidas a termo e pré-termo. Audiol Commun Res. 2016;21(0):e1672. http://dx.doi.org/10.1590/2317-64312016-1672.

28. Silva LAF, Couto MIV, Tsuji RK, Bento RF, Carvalho ACM, Matas CG. Auditory cortical maturation in a child with cochlear implant: analysis of electrophysiological and behavioral measures. Case Rep Otolaryngol. 2015;2015:890508. http://dx.doi.org/10.1155/2015/890508. PMid:26881163.

29. Wunderlich JL, Cone-Wesson BK, Shepherd R. Maturation of the cortical auditory evoked potential in infants and young children. Hear Res. 2006;212(1-2):185-202. http://dx.doi.org/10.1016/j.heares.2005.11.010. PMid:16459037.

30. Roth AM. Sinais de psíquico em bebês na faixa etária de 3 a 9 meses e sua relação com variáveis obstétricas, sociodemográficas e psicossociais [tese]. Santa Maria (RS): Universidade Federal de Santa Maria; 2016. 190 p.

\section{Author contributions}

ICR: Participated in the planning of the study, collection, analysis and interpretation of the data and writing of the article; IMF: Article Writing; ABM: data analysis and article statistics; EPVB: Participated, as an advisor, planning the study, analysis, interpretation of the data and writing of the article; APRS: Participated, as an advisor, in the planning of the study, analysis, interpretation of the data and writing of the article. 